\title{
CYTOMEGALOVIRUS IMMUNOGLOBULIN G AVIDITY INDEX AMONG BLOOD DONORS IN ALEXANDRIA, EGYPT
}

\author{
Aleya Abdel Gawad', Mona Hashish ${ }^{1}$, Amani Abaza ${ }^{1}$, Aisha El-Kayal2 \\ ${ }^{1}$ Microbiology Department, High Institute of Public Health, Alexandria University, Alexandria, Egypt \\ ${ }^{2}$ Alexandria Regional Blood Transfusion Centre, Alexandria, Egypt
}

\section{SUMMARY}

Background and Aim: Transfusion transmitted diseases (TTD) are a major challenge to transfusion services all over the world. Cytomegalovirus (CMV) is considered one of the main viruses associated with blood transfusion. As CMV screening is not included in routine screening tests done for donated blood in blood banks in Egypt, the detection of CMV Immunoglobulin G ( $\mathrm{lg} G$ ) avidity needs to be tested for being a useful tool to diagnose recent infection among blood donors. The aim of this work was to study CMV IgG avidity index (Al) among blood donors.

Methods: A total of 88 blood samples were collected from the non-remunerated volunteer blood donors who attended the Alexandria Regional Blood Transfusion Centre. A quantitative enzyme linked immunosorbent assay for the avidity detection of the specific lgG antibodies to CMV in human serum samples was used.

Results: Eighty five studied blood donors (96.6\%) were positive for CMV IgG. Eighty one donors (95.3\%) showed high avidity (>45.0\%). Regarding the remaining four CMV IgG positive donors; three had medium avidity $(<45.0 \%)$ and only one had a low avidity of $<25.0 \%$. A moderate agreement of $42.4 \%$ was found between IgG concentration and avidity.

Conclusions: CMV seroprevalence was found to be high among volunteer blood donors, where age and gender were statistically significant factors associated with CMV IgG concentration. The use of the avidity assay as a screening tool for CMV among blood donors is highly suggested. The exclusion of the low and medium Al units will ensure the availability of a safe stock of blood units, hence eliminating the risk of CMV transmission to vulnerable groups.

Key words: transfusion transmitted diseases, cytomegalovirus, cytomegalovirus immunoglobulin G, avidity index, enzyme linked immunosorbent assay

Address for correspondence: A. F. Abaza, Microbiology Department, High Institute of Public Health, Alexandria University, 165 El Horreya Avenue, Alexandria, Egypt. E-mail: amani_abaza@yahoo.com

http://dx.doi.org/10.21101/cejph.a4157

\section{INTRODUCTION}

Transfusion transmitted diseases (TTD) are a major challenge to transfusion services all over the world (1). Transfusion of unscreened cellular components leads to a TTD incidence of approximately $30 \%$ in seronegative recipients (2). The presence of viruses in blood cells or plasma of asymptomatic donors is the major risk factor for transmitting infectious agents through blood transfusion. The main viruses associated with transfusion related infections are hepatitis viruses, retroviruses and cytomegalovirus (CMV) (3).

CMV is the largest member of the herpesviridae family (4). It has the ability to remain latent within the T-cells, endothelial cells and monocyte-derived macrophages and may be reactivated from latently infected cells after blood transfusion $(5,6)$. CMV seems to have a large impact on immune parameters in later life and may contribute to increased morbidity and eventual mortality (7).

Several studies have reported that CMV immunoglobulin G (CMV IgG) is transmitted by blood transfusion from healthy seropositive donors to susceptible recipients (8-10). Vulnerable groups to serious illness caused by this virus are immunocompromised hosts, neonates and pregnant women $(5,6)$. Exclusion of seropositive blood units and leucodepletion are the two main strategies to minimize CMV transmission to high risk recipients (11).

CMV has a worldwide distribution. It is more widespread in developing countries and in communities with lower socioeconomic status. Between $50-80 \%$ of adults in developed countries and up to $100 \%$ in developing countries are infected with human CMV. It represents the most significant viral cause of birth defects in industrialized countries (12). Several studies have demonstrated a strong link between primary CMV infection of the mother and in utero CMV transmission. The risk of congenital infection is approximately $40 \%$ in babies born to mothers who acquire a primary (initial) CMV infection after conception; in contrast, the risk is only about $1 \%$ in infants born to mothers who have evidence of CMV infection (i.e. circulating CMV antibodies) before conception. The established link between primary CMV infection during pregnancy and congenital infection makes identification of pri- 
mary CMV infection an important goal in maternal and neonatal health care (13). Applying this concept to donated blood - safe blood for transfusion would be that without evidence of primary CMV infection (11).

As it has the ability to remain latent, CMV infection in immunocompetent persons is subclinical and the diagnosis mainly relies on serology (12).

CMV specific IgM is an extremely sensitive marker of primary CMV infection. Unfortunately, CMV IgM detection is not specific for primary infection due to its production following reinfection or reactivation in some individuals. Likewise, demonstration of increasing levels of CMV IgG overtime is an impractical approach since most patients already show high IgG levels in the first tested serum sample. Therefore, when IgM is detected, it is advisable to use a complementary test to establish the date of CMV infection. The most useful test is the measurement of the IgG avidity index which has been shown to help in distinguishing primary from past or recurrent infection (14).

As CMV screening is not included in routine screening tests done for donated blood in blood banks in Egypt, the detection of CMV Ig G avidity needed to be tested for being a useful tool to diagnose recent infection among blood donors. This work aimed to study CMV Ig G avidity index among blood donors.

\section{MATERIALS AND METHODS}

This cross sectional study was carried out through a three month period from July to September 2010. It involved 88 volunteer blood donors who attended the Alexandria Regional Blood Transfusion Centre (ARBTC), one of the Ministry of Health and Population Centres.

Non remunerated volunteer blood donors were selected according to the standard operating procedures adopted by the Donor Care Department (DCD) in ARBTC $(15,16)$. Selection criteria and medical examination for blood donors were applied and performed by the designated medical staff.

\section{Sample Selection and Size}

Based on a previous study on CMV among blood donors: the urgency for screening (17), assuming prevalence of CMV IgG $=67.4 \%$, precision of 17 , and alpha of 0.05 , a minimum sample size required was calculated to be 63 (18). Systemic randomization was selected as the method to choose samples for the present study from the daily blood donors attending ARBTC. This was done every other day starting from first of July 2010 until a total of 88 blood samples were collected.

\section{Sample Collection and Processing}

A total of 88 blood samples were collected from the nonremunerated volunteer blood donors in ARBTC. Five $\mathrm{mL}$ of blood samples were collected under aseptic techniques from blood units into vacutainer tubes. All tubes were centrifuged at 3,500 rpm for five minutes and the clear sera were collected aseptically in labeled eppendorf tubes and stored at $-20^{\circ} \mathrm{C}$ until tested. Repeated thawing and freezing was avoided. Haemolyzed, lipemic or turbid samples were excluded.

\section{Data Collection Method}

To ensure the donor's privacy, personal data (name, address, phone numbers, etc.) were not revealed. Data concerning blood donors as age, gender, residence, occupation, blood groups, Rhesus factor $(\mathrm{Rh})$, and results of routine serological screening tests - Hepatitis C virus antibodies (HCVAbs), hepatitis B surface antigen (HBsAg), Trepnoma pallidum antibodies (T. pallidum Abs) for syphilis and human immunodeficiency virus antibodies (anti HIV) were obtained from the information technology unit in ARBTC and recorded in a sheet.

\section{Detection of CMV IgG Avidity by ELISA}

CMV IgG was detected by avidity test kit (Bouty, Italy). It is a quantitative ELISA for the avidity detection of the specific IgG antibodies to CMV in human serum or plasma samples $(13,19)$.

The manufacturer's instructions were strictly followed. Each of the tested samples was placed in two adjacent wells ( $a$ and $b$ ). After the first incubation all wells were washed with the wash buffer followed by dispensing of wash buffer into wells "a" and of avidity solution into well "b". The conjugate substrate and stop solution were added as recommended.

\section{Calculation of Results}

Calculation was performed by plotting the O.D. of each calibrator (ordinate) against calibrator concentration (abscissa) on suitable graph paper, linking points by straight segments. Concentrations of controls and samples were then read from the fragmented curve by interpolation with the O.D. This was done for the samples having concentrations $<600 \mathrm{mU} / \mathrm{mL}$.

For the samples having concentrations $>600 \mathrm{mU} / \mathrm{mL}(20$ samples), linear and quadratic regression analysis were done. Quadratic analysis was fitting with observed values (Fig. 1, 2).

In order to correlate the analytical results to the avidity (\%) of the samples, results were determined using the following formula:

$$
\text { Avidity }(\%)=\frac{\text { Residual IgG well "b" }}{\text { Total IgG well "a" }} \times 100
$$

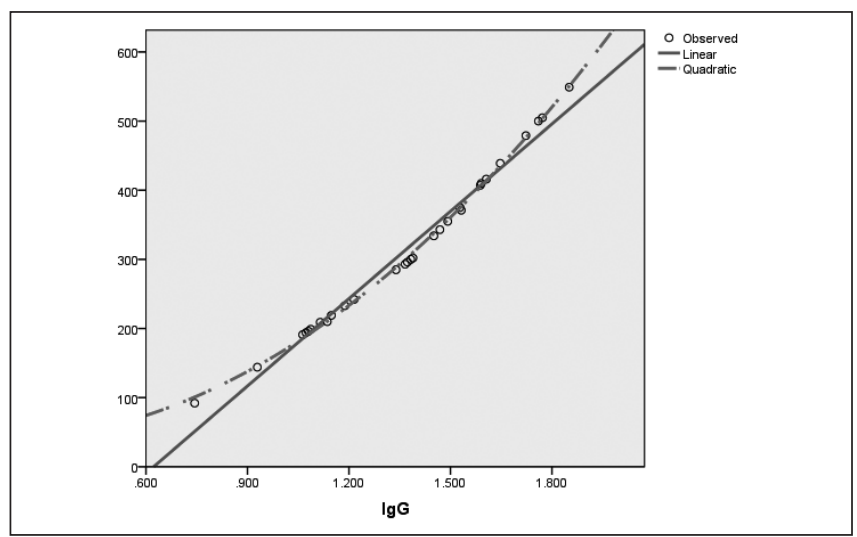

Fig. 1. Linear and quadratic regression lines for Ig G concentrations of the first ELISA plate.

Regression equation to estimate concentration: Conc $=42.845-54.093 \times \lg G+$ $177.374 \times \lg G^{2}$ 


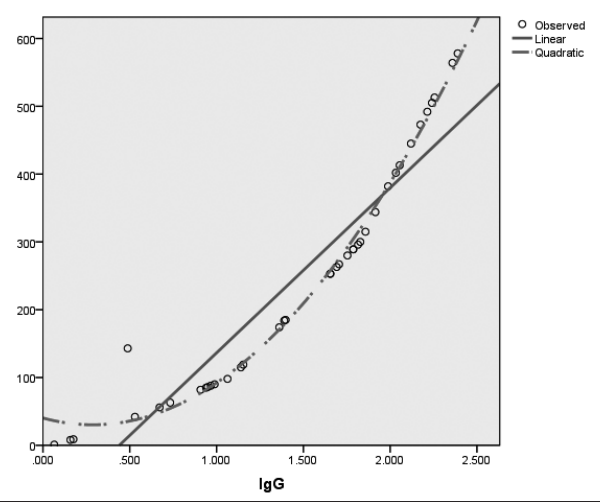

Fig. 2. Linear and quadratic regression lines for IgG concentrations of the second ELISA plate.

Regression equation to estimate concentration: Conc $=40.261-69.678 \times \lg G+$ $121.586 \times \lg G^{2}$

\section{Interpretation of Results}

Total $\mathrm{IgG}$ readings less than calibrator $1(10 \mathrm{mU} / \mathrm{mL})$ were considered negative and the rest were positive for CMV IgG. The positive results were subject to calculation of avidity using the previous equations.
The following interpretive criteria based on clinical trials performed on samples representative of the European population were compared to the results:

Avidity $<25 \% \rightarrow$ low avidity meaning primary CMV infection occurred during the last three months.

Avidity of $25-45 \% \rightarrow$ medium avidity meaning primary CMV infection occurred during the last six months.

Avidity $>45 \% \rightarrow$ high avidity meaning to exclude primary infection within the last three months.

The results of the study were categorized at $45 \%$ avidity and as percentiles for total $\mathrm{IgG}$ concentrations as shown in Table 1 to allow proper comparison with the different variables studied.

A percentile is an observation below which lies a percentage of the studied ordered observations. The 25 th percentile is

Table 1. Percentiles for IgG concentrations

\begin{tabular}{|c|c|}
\hline Percentiles & Concentration \\
\hline 25 th & 194.5 \\
\hline 50 th & 324.5 \\
\hline 75 th & 560.25 \\
\hline
\end{tabular}

Table 2. Demographic and clinical data with respect to CMV seroprevalence of the 88 blood donors

\begin{tabular}{|c|c|c|c|c|}
\hline Data & Category & Number & $\%$ & CMV seroprevalence (\%) \\
\hline \multirow{2}{*}{$\begin{array}{l}\text { Age group } \\
\text { (years) }\end{array}$} & Less than 30 & 42 & 47.7 & 95.2 \\
\hline & 30 or more & 46 & 52.3 & 97.8 \\
\hline \multirow{2}{*}{ Gender } & Female & 21 & 23.9 & 100.0 \\
\hline & Male & 67 & 76.1 & 95.5 \\
\hline \multirow{5}{*}{ Occupation } & Professional & 22 & 25.0 & 90.9 \\
\hline & Employee & 19 & 21.6 & 94.7 \\
\hline & Worker & 16 & 18.2 & 100.0 \\
\hline & Student & 19 & 21.6 & 100.0 \\
\hline & Housewife/unemployed & 12 & 13.6 & 100.0 \\
\hline \multirow{2}{*}{ Residence } & Alexandria & 86 & 97.7 & 96.5 \\
\hline & El Behira & 2 & 2.3 & 100.0 \\
\hline \multirow{2}{*}{$\mathrm{Rh}$} & Positive & 79 & 89.8 & 96.2 \\
\hline & Negative & 9 & 10.2 & 100.0 \\
\hline \multirow{4}{*}{ ABO blood groups } & A & 32 & 36.4 & 96.9 \\
\hline & $B$ & 26 & 29.5 & 96.2 \\
\hline & $A B$ & 5 & 5.7 & 100.0 \\
\hline & 0 & 25 & 28.4 & 96.0 \\
\hline \multicolumn{5}{|c|}{ Routine serological tests ${ }^{\mathrm{a}}$} \\
\hline \multirow{2}{*}{ HBsAg } & Negative & 84 & 95.5 & 96.4 \\
\hline & Positive $^{b}$ & 4 & 4.5 & 100.0 \\
\hline \multirow{2}{*}{ HCV Abs } & Negative & 86 & 97.7 & 96.5 \\
\hline & Positive $^{b}$ & 2 & 2.3 & 100.0 \\
\hline \multirow{2}{*}{ T. pallidum Abs } & Negative & 87 & 98.9 & 96.6 \\
\hline & Positive & 1 & 1.1 & 100.0 \\
\hline
\end{tabular}

aNone of the donors was HIV positive.

'One donor had HBV and HCV co-infection 
also known as the first quartile (Q1), the 50th percentile as the median or second quartile (Q2), and the 75th percentile as the third quartile (Q3)

One definition of percentile, often given in texts, is that the $\mathrm{P}$-th percentile $(0 \leq \mathrm{P}<100)$ of $\mathrm{N}$ ordered values (arranged from least to greatest) is obtained by first calculating the (ordinal) rank

$$
n=\frac{P}{100} \times N+\frac{1}{2}
$$

Rounding the result to the nearest integer and then taking the value that corresponds to that rank.

(Note that the rounded value of $\mathrm{n}$ is just the least integer which exceeds $\frac{P}{100} \times N \quad$ ).

\section{Statistical Analysis}

The data of the study were tabulated and statistically analyzed using SPSS software version 19.0. Statistical tests used in the analysis included the arithmetic mean, standard deviation, regression equations, Fisher's exact test (FET), p value $\leq 0.05$ was considered statistically significant. It also included $t$ test for significance of $r$, independent samples t-test, Kappa statistics (20-22), Kappa coefficient, Kappa agreement percent less than $25 \% \rightarrow$ low agreement, $25-74 \% \rightarrow$ moderate agreement, $75-99 \%$ $\rightarrow$ high agreement, $100 \% \rightarrow$ perfect agreement.

\section{RESULTS}

Among the studied 88 blood donors, 85 (96.6\%) were positive for CMV IgG. Total IgG ranged from $42.0 \mathrm{mU} / \mathrm{mL}$ to $1,333.9 \mathrm{mU} /$ $\mathrm{mL}$ with a mean of $442.6 \mathrm{mU} / \mathrm{mL} \pm 328.5 \mathrm{mU} / \mathrm{mL}$. The avidity percentage ranged from $17.8 \%$ to $99.3 \%$ with a mean of $77.3 \% \pm 13.9$.

Eighty one donors $(95.3 \%)$ showed high avidity $(>45.0 \%)$. Regarding the remaining four CMV IgG positive donors; three had medium avidity $(<45.0 \%)$ and only one had a low avidity of $<25.0 \%$.

Demographic and clinical data with respect to CMV seroprevalence are shown in Table 2. The mean age was $30.8 \pm 8.6$ years ranging between 18 and 51 years. CMV seroprevalence among those less than 30 years old was $95.2 \%$, while it was $97.8 \%$ among those aged 30 years or more. A $62.5 \%$ of the donors less than 30 years old had total $\mathrm{IgG}$ concentrations below the 50th percentile. On the other hand, the majority of the elder group aging 30 years or more $(64.4 \%)$ had concentrations above the 50th percentile. This was statistically significant $(\mathrm{p}<0.05)$ (Table 3 ).

Of the 88 blood donors, 67 (76.1\%) were males and $21(23.9 \%)$ females with a CMV seroprevalence of $95.5 \%$ and $100.0 \%$, respectively. The majority of female donors $(76.2 \%)$ had total IgG concentrations above the 50th percentile, while the majority of male donors $(56.3 \%)$ had total IgG concentrations below 50 th percentile. These results were statistically significant $(\mathrm{p}<0.05)$ (Table 4$)$.

A moderate agreement of $42.4 \%$ was found between IgG concentration and avidity $\%$ (Table 5 ).

Table 3. Relation between CMV total IgG concentrations and avidity level of the 85 blood donors and their age

\begin{tabular}{|c|c|c|c|c|}
\hline \multirow{3}{*}{$\begin{array}{l}\text { Age group } \\
\text { (years) }\end{array}$} & \multicolumn{4}{|c|}{ CMV } \\
\hline & \multicolumn{2}{|c|}{ Total $\lg \mathrm{G}$ concentration $(\mathrm{mU} / \mathrm{mL})$} & \multicolumn{2}{|c|}{ Avidity level } \\
\hline & $\begin{array}{c}<50 \text { th percentile } \\
\quad n=41\end{array}$ & $\begin{array}{l}>\text { 50th percentile } \\
\quad n=44\end{array}$ & $\begin{array}{c}\text { Low }(<45.0 \%) \\
n=4\end{array}$ & $\begin{array}{c}\text { High ( } 45.0 \% \text { or more) } \\
n=81\end{array}$ \\
\hline $\begin{array}{l}\text { Less than } 30 \\
n=40\end{array}$ & $25(62.5 \%)$ & $15(37.5 \%)$ & $2(5.0 \%)$ & $38(95.0 \%)$ \\
\hline \multirow[t]{2}{*}{$\begin{array}{l}30 \text { or more } \\
n=45\end{array}$} & $16(35.6 \%)$ & $29(64.4 \%)$ & $2(4.4 \%)$ & $43(95.6 \%)$ \\
\hline & FET: 6.085 & $p=0.017^{*}$ & FET: 0.015 & $p=0.904$ \\
\hline
\end{tabular}

*Statistically significant

FET: Fisher's exact test

Table 4. Relation between CMV total IgG concentrations and avidity level of the 85 blood donors and their gender

\begin{tabular}{|c|c|c|c|c|}
\hline \multirow{3}{*}{ Gender } & \multicolumn{4}{|c|}{ CMV } \\
\hline & \multicolumn{2}{|c|}{ Total IgG concentration (mU/mL) } & \multicolumn{2}{|c|}{ Avidity level } \\
\hline & $\begin{array}{c}<50 \text { th percentile } \\
\quad n=41\end{array}$ & $\begin{array}{c}>\text { 50th percentile } \\
\quad n=44\end{array}$ & $\begin{array}{c}\text { Low }(<45.0 \%) \\
n=4\end{array}$ & $\begin{array}{c}\text { High ( } 45.0 \% \text { or more) } \\
n=81\end{array}$ \\
\hline $\begin{array}{l}\text { Female } \\
n=21\end{array}$ & $5(23.8 \%)$ & $16(76.2 \%)$ & $1(4.8 \%)$ & $20(95.2 \%)$ \\
\hline \multirow[t]{2}{*}{$\begin{array}{l}\text { Male } \\
n=64\end{array}$} & $36(56.3 \%)$ & $28(43.7 \%)$ & $3(4.7 \%)$ & $61(95.3 \%)$ \\
\hline & FET: 6.664 & $p=0.017^{\star}$ & FET: 0.002 & $p=0.988$ \\
\hline
\end{tabular}

*Statistically significan

FET: Fisher's exact test 
Table 5. Relation between CMV total IgG and avidity level of the 85 blood donors

\begin{tabular}{|c|c|c|}
\hline \multicolumn{3}{|c|}{ CMV } \\
\hline \multirow[b]{2}{*}{ Avidity level* } & \multicolumn{2}{|c|}{ Total IgG concentration } \\
\hline & $\begin{array}{c}>\text { 50th percentile } \\
\qquad n=44\end{array}$ & $\begin{array}{c}<50 \text { th percentile } \\
n=41\end{array}$ \\
\hline $\begin{array}{l}>50 \text { th percentile } \\
n=43\end{array}$ & $19(44.2 \%)$ & $24(55.8 \%)$ \\
\hline $\begin{array}{l}<50 \text { th percentile } \\
n=42\end{array}$ & $25(59.5 \%)$ & $17(40.5 \%)$ \\
\hline
\end{tabular}

*Percentiles for avidity \% (for statistical reasons, this classification was only used in this table)

Percentiles Avidity

25th $\quad 71.4 \%$

50th $\quad 78.5 \%$

75th $87.0 \%$

\section{DISCUSSION}

CMV is considered one of the main viruses associated with blood transfusion. The virus has a worldwide distribution. It is more common in developing countries where most adults have been shown to be infected with CMV (23-25).

In the present study, CMV seroprevalence was found to be $96.6 \%$ among volunteer blood donors. Nearly similar results were reported in previous studies which revealed that CMV seroprevalence ranged from $92-97 \%$ (26-30). Lower rates of $52.5 \%, 67.4 \%$ and $83.4 \%$ were reported in Egypt by Mourad et al., Mussa et al., and El-Saady $(17,31,32)$. In western countries, much lower rates were documented ranging from $30-60 \%(33,34)$. The difference in CMV seroprevalence could probably be explained by the difference in techniques used for the diagnosis or the implementation of certain selection criteria for the studied donors.

Age is one of the most important factors that should be tackled when a study is dealing with CMV seroprevalence. In the current work, CMV seroprevalence among those less than 30 years old was $95.2 \%$, while it was $97.8 \%$ among those aged 30 years or more. In addition, the results revealed that $37.5 \%$ of blood donors in the age group less than 30 years had IgG concentrations above the 50th percentile versus $64.4 \%$ in the elder group. This was statistically significant implying that there was an increasing trend of total CMV IgG with age. This is consistent with other reports in Egypt and in many parts of the world (28, 31, 35-39). Furthermore, many researchers remarked that CMV seropositivity was increasing among certain age groups $(10,27)$.

CMV was lowest in the extremes of age (26). In Egypt, El-Saady noted that the highest percentage was in the age group of 20-29 years (32). Another study conducted in Bida, Nigeria on pregnant females showed that the highest prevalence of CMV (31.2\%) was in the age group of $21-25$ years followed by $22.9 \%$ in the $26-30$ years age group. Thus, CMV seroprevalence is high in the age group of 21-30 years when compared to other age groups (40). In the latter study, they justified this trend by the fact that the 21-30 years age group represents the active and sexually matured youths with the tendency toward sexual promiscuity, multiple sexual partnerships and its resultant likelihood of high infection rates. Furthermore, they explained the increased rate in multigravidae as a result of longer periods of marriage. This could be supported by previous studies among promiscuous people having high infection rates of sexually transmitted diseases (40). However, this may not be totally applicable to our religious community. Nevertheless, the increased incidence in multigravidae may be a considerable fact.

CMV has emerged as a significant cause of morbidity and mortality specially when transfused to risky groups like children and immunocompromised adults. In many developed countries, it is not mandatory to screen donated blood for CMV in blood banks $(8,11)$. That is why Kothari et al. suggested that the estimation of the seroprevalence among voluntary blood donors may be of help to decide whether screening for CMV would eliminate transmission of infection to high-risk groups (29).

Based on the high seroprevalence rates reported in many studies, elimination of CMV positive units would deprive blood banks from a considerable proportion of blood units. The rationale of exclusion of CMV transmissible blood units of low and medium $\mathrm{AI}$ (avidity index) would provide a reasonable stock of CMV safe units of high AI. Thus, avidity is considered a recent screening test for blood donors, which needs to be evaluated. It was proven to be successful in the differentiation between primary and secondary infection among different subjects especially pregnant women. This was the objective of a number of researches $(14,19,39,41$, 42). Three laboratories followed pregnancy outcomes to identify cases of congenital CMV infection; all found a strong association between low CMV IgG avidity during pregnancy and increased risk of in utero transmission $(14,43,44)$. The Paris and Bologna groups reported that all women who had CMV-infected offspring exhibited low IgG avidity $(14,42,43)$. Similarly, one paper from the Brussels group reported that $89 \%$ of transmitting women exhibited low IgG avidity (44).

CMV IgG avidity is an effective tool for assessing risk of transmission (13). Avidity has been investigated among risk groups such as immunocompromised patients (40, 45-47), pregnant women $(15,37,39,40)$, and neonates $(48,49)$. Researchers have also studied avidity in immunocompetent persons $(39,50)$.

In the present study, the avidity percentage had a minimum of $17.8 \%$ and a maximum of $99.3 \%$ with a mean of $77.3 \%$ and SD of 13.9. Of the 85 tested blood donors, 81 (95.3\%) donors showed high avidity $(>45 \%)$. Three donors had medium avidity $(<45 \%)$ and one had a low avidity $(<25 \%)$. The relation between CMV total IgG concentration and avidity level was studied. In a trial to overcome the low number of cases in each category, percentiles for total IgG concentrations and avidity level were used. Kappa coefficient was used yielding a moderate percent of agreement $42.4 \%$. Of the blood donors with avidity above the 50th percentile, 
$55.8 \%$ had IgG concentrations below the 50th percentile, while $59.5 \%$ of those with avidity below the 50th percentile, had IgG concentrations above the 50th percentile. However, no significant difference was found between these results.

Lazzarotto et al., tested serum samples from 96 immunocompetent blood donors. Thirty-two blood donors were IgG positive as judged by both conventional ELISA and Western blotting. Among these, 31 were shown to have a high AI and one showed a low AI. Furthermore, this study was the first work in which the maturation of antibodies after CMV infection was correlated with virological and serological parameters in both pregnant women and solid organ transplantation (SOT) recipients. Their results demonstrated that the CMV IgG avidity test differentiates primary from non primary CMV infections. Moreover, the results obtained showed that in both populations there was a progressive acquisition of antibody avidity within the first 6 months after primary infection. In fact, for both populations 6 months seems to be long enough to guarantee the full maturation of antibodies (41). This result was in disagreement with the data of Lutz et al. (46), who found that in SOT recipients approximately one year is needed for IgG to mature to high avidity in contrast to the 3 to 6 months expected in immunocompetent subjects.

Another study conducted by Bodeus et al., found that 72/79 of the patients with past infection had an $\mathrm{AI}>65 \%$ and all but one had an $\mathrm{AI}>50 \%$. In pregnant women, in the case of a primary infection within the past 3 months, AIs were usually $(51 / 53)<50 \%$ and never $>65 \%$. Among the $49 \mathrm{IgM}$ positive pregnant women who lacked a seroconversion history, 38 had AI $>65 \%$ suggestive of an infection that had occurred at least 3 months earlier, 11 had an $\mathrm{AI}<50 \%$, suggestive of a recent primary infection (42).

Kanengisser et al. agreed with the previous study that $\mathrm{IgG}$ avidity $>65 \%$ is a reliable indicator of past infection. This study was carried out on patients with positive IgM detected during the first trimester of pregnancy (52).

Furthermore, Boppana and Britt suggested that the affinity maturation of maternal antibody may be critical in preventing maternal-foetal transmission of CMV. In their reports, non transmitters showed significantly higher antibody avidities than transmitters (53).

Kumar et al. explained that due to the high seropositivity of CMV IgG discarding blood positive for CMV IgG is not feasible, but blood screened positive for CMV IgM is recommended to be discarded. But in a developing country like India, screening for IgM antibody on a routine basis may not be feasible, given the likely yield to be low and the cost being high. Universal leucodepletion of blood is ideal and is in vogue in the western world, but it is still not implemented in developing countries due to economical factors (54).

In Canada, the use of CMV-safe blood has been recommended for CMV seronegative patients with newly diagnosed malignant disease for whom bone marrow transplantation is a future option (33).

The natural history of CMV infection indicates that immunoprophylaxis will protect against CMV disease (55). Until this is available on the therapeutic level, the prevention of transfusion transmitted CMV infection is recommended for CMV seronegative immunocompromised patients. This can be achieved by using CMV seronegative blood and blood products or white blood cells depleted blood products. Also large scale screening of blood donors for CMV using different assays is recommended $(27,31)$.
It can be concluded from this study that CMV seroprevalence was high among volunteer blood donors. Age and gender were statistically significant factors associated with CMV IgG concentration. Relatively a low number (4) of blood donors had low and medium AI. Low and medium AI imply that they can effectively transmit CMV infections to recipients.

\section{CONCLUSIONS AND RECOMMENDATIONS}

The use of the avidity assay as a screening tool for CMV among blood donors is highly suggested. The exclusion of the low and medium AI units will ensure the availability of a safe stock of blood units, hence eliminating the risk of CMV transmission to vulnerable groups. In addition, age and gender are two important factors that should be carefully studied to identify the target groups for follow up and implementation in future studies. Finally, further studies focusing on the relation between total IgG concentrations and avidity level should be considered.

\section{Study Limitations}

One limitation of this study is the small number of samples tested, as we were restricted by the cost of used kits and our affordable budget, though we used a sample size that was above the statistically calculated minimum number, based on a previous study on the urgency for CMV screening among blood donors.

Another limitation was that we could not follow up the blood units with low avidity levels to monitor infections among recipients.

\section{REFERENCES}

1. Pass RF. Cytomegalovirus. In: Fields BN, Knipe DM, Howley PM, Griffin DE, editors. Fields' virology. 4th ed. Philadelphia: Lippincott Williams \& Wilkins; 2001. p. 2675-706.

2. Schottstedt V, Blümel J, Burger R, Drosten C, Gröner A, Gürtler L, et al. Human Cytomegalovirus (HCMV) - Revised. Transfus Med Hemother. 2010;37(6):365-375

3. Zia M, Taha HM, Ricci C. Transfusion-transmitted diseases [Internet]. Medscape; 2014 [cited 2015 Oct 8]. Available from: http://emedicine. medscape.com/article/1389957-overview.

4. Britt WJ, Boppana S. Human cytomegalovirus virion proteins. Hum Immunol. 2004 May;65(5):395-402.

5. Koffron AJ, Mueller KH, Kaufman DB, Stuart FP, Patterson B, Abecassis MI. Direct evidence using in situ polymerase chain reaction that the endothelial cell and T-lymphocyte harbor latent murine cytomegalovirus. Scand J Infect Dis Suppl. 1995;99:61-2.

6. Jarvis MA, Nelson JA. Human cytomegalovirus persistence and latency in endothelial cells and macrophages. Curr Opin Microbiol. 2002 Aug;5(4):403-7.

7. Caruso C, Buffa S, Candore G, Colonna-Romano G, Dunn-Walters D, Kipling D, et al. Mechanisms of immunosenescence. Immun Ageing. 2009 Jul 22;6:10. doi: 10.1186/1742-4933-6-10.

8. Bowden RA. Transfusion-transmitted cytomegalovirus infection. Hematol Oncol Clin North Am. 1995 Feb;9(1):155-66.

9. Larsson S, Söderberg-Nauclér C, Möller E. Productive cytomegalovirus (CMV) infection exclusively in CD13-positive peripheral blood mononuclear cells from CMV-infected individuals: implications for prevention of CMV transmission. Transplantation. 1998 Feb 15;65(3):411-5.

10. Amarapal P, Tantivanich S, Balachandra K. Prevalence of cytomegalovirus in Thai blood donors by monoclonal staining of blood leukocytes. Southeast Asian J Trop Med Public Health. 2001 Mar;32(1):148-53.

11. Ziemann M, Hennig H. Prevention of transfusion-transmitted cytomegalovirus infections: which is the optimal strategy? Transfus Med Hemother. 2014 Feb;41(1):40-4. 
12. Britt WJ, Alford CA. Cytomegalovirus. In: Fields BN, Knipe DM, Howley PM, editors. Fields virology. 3rd ed. Philadelphia: Raven Press; 1996. p. 2493-523.

13. Prince HE, Lapé-Nixon M. Role of cytomegalovirus (CMV) IgG avidity testing in diagnosing primary CMV infection during pregnancy. Clin Vaccine Immunol. 2014 Oct;21(10):1377-84.

14. Grangeot-Keros L, Mayaux MJ, Lebon P, Freymuth F, Eugene G, Stricker $\mathrm{R}$, et al. Value of cytomegalovirus (CMV) IgG avidity index for the diagnosis of primary CMV infection in pregnant women. J Infect Dis. 1997 Apr;175(4):944-6.

15. Britten A, Ala FA, El Nageh M, editors. Blood transfusion: a basic text. WHO regional publications. Eastern Mediterranean series, no 7. Alexandria: WHO Regional Office for the Eastern Mediterranean; 1994.

16. Sibinga CTS. Blood transfusion and blood components. WHO regional publications. Eastern Mediterranean series, no 12. Alexandria: WHO Regional Office for the Eastern Mediterranean; 1995.

17. Mourad MI, Ashour MS, Mourad ZI. Cytomegalovirus (CMV) among blood donors: the urgency for screening. Bull High Inst Public Health. 1998;28(2):185-94

18. Chow SC, Shao J, Wang H. Sample size calculation in clinical research. Chapman and Hall/CRC biostatistics series. 2nd ed. Boca Raton: Chapman \& Hall/CRC; 2008.

19. Baccard-Longere M, Freymuth F, Cointe D, Seigneurin JM, GrangeotKeros L. Multicenter evaluation of a rapid and convenient method for determination of cytomegalovirus immunoglobulin G avidity. Clin Diagn Lab Immunol. 2001 Mar;8(2):429-31.

20. Kulkarni H. Choosing a statistical method, with automatic internet searching [Internet]. 2002 [cited 2015 Oct 8]. Available from: http://vz.truni. sk/prednasky/statistika/choosing.html.

21. Agreement between categorical measurements: Kappa Statistics [Internet]. [cited 2015 Oct 8]. Available from: http://people.dbmi.columbia. edu/homepages/chuangi/kappa.

22. Basic concepts and definitions [Internet]. [cited 2016 Nov 23]. Available from: http://gim.unmc.edu/dxtests/reviewof.htm.

23. Ho M. Epidemiology of cytomegalovirus infections. Rev Infect Dis. 1990 Sep-Oct;12 Suppl 7:S701-10.

24. Stagno S, Dworsky ME, Torres J, Mesa T, Hirsh T. Prevalence and importance of congenital cytomegalovirus infection in three different populations. J Pediatr. 1982 Dec;101(6):897-900.

25. Enright AM, Prober CG. Herpesviridae infections in newborns: varicella zoster virus, herpes simplex virus, and cytomegalovirus. Pediatr Clin North Am. 2004 Aug;51(4):889-908, viii.

26. Alao OO, Joseph DE, Mamman A, Banwat EB. The seroprevalence of cytomegalovirus antibodies among prospective blood donors in Jos. Niger J Med. 2008 Apr-Jun;17(2):198-200.

27. Adjei A, Armah H, Narter-Olaga E. Seroprevalence of cytomegalovirus among some voluntary blood donors at the 37 military hospital, Accra, Ghana. Ghana Med J. 2006 Sep;40(3):99-104.

28. Pultoo A, Meetoo G, Pyndiah MN, Khittoo G. Seroprevalence of cytomegalovirus infection in Mauritian volunteer blood donors. Indian J Med Sci. 2001 Feb;55(2):73-8

29. Kothari A, Ramachandran VG, Gupta P, Singh B, Talwar V. Seroprevalence of cytomegalovirus among voluntary blood donors in Delhi, India. J Health Popul Nutr. 2002 Dec;20(4):348-51.

30. Gargouri J, Elleuch H, Karray H, Rekik H, Hammami A. Prevalence of anti-CMV antibodies in blood donors in the Sfax region (value in blood transfusion). Tunis Med. 2000 Aug-Sep;78(8-9):512-7. (In French.)

31. Mussa EA, El Sayed MK, Hafez AM. Prevalence of cytomegalovirus IgG antibody in blood donors. Egypt J Med Lab Sci. 2005;14(1):41-7.

32. El-Saady AS. Detection of cytomegalovirus infection among blood donors [dissertation]. Alexandria: Alexandria University, Faculty of Medicine; 1992.

33. Nicolle LE, Minuk GY, Postl B, Ling N, Madden DL, Hoofnagle JH. Cross-sectional seroepidemiologic study of the prevalence of cytomegalovirus and herpes simplex virus infection in a Canadian Inuit (Eskimo) community. Scand J Infect Dis. 1986;18(1):19-23.

34. Preiksaitis JK, Desai S, Vaudry W, Roberts S, Akabutu J, Grundy P, et al. Transfusion- and community-acquired cytomegalovirus infection in children with malignant disease: a prospective study. Transfusion. 1997 Sep;37(9):941-6.

35. Sheevani, Jindal N, Aggarwal A. A pilot seroepidemiological study of cytomegalovirus infection in women of child bearing age. Indian J Med Microbiol. 2005 Jan;23(1):34-6.

36. Seale H, MacIntyre CR, Gidding HF, Backhouse JL, Dwyer DE, Gilbert L. National serosurvey of cytomegalovirus in Australia. Clin Vaccine Immunol. 2006 Nov;13(11):1181-4
37. Venkitaraman AR, Seigneurin JM, Lenoir GM, John TJ. Infections due to the human herpesviruses in southern India: a seroepidemiological survey. Int J Epidemiol. 1986 Dec;15(4):561-6.

38. Gratacap-Cavallier B, Bosson JL, Morand P, Dutertre N, Chanzy B, Jouk PS, et al. Cytomegalovirus seroprevalence in French pregnant women: parity and place of birth as major predictive factors. Eur J Epidemiol. 1998 Feb;14(2):147-52.

39. Dollard SC, Staras SA, Amin MM, Schmid DS, Cannon MJ. National prevalence estimates for cytomegalovirus IgM and IgG avidity and association between high IgM antibody titer and low IgG avidity. Clin Vaccine Immunol. 2011 Nov;18(11):1895-9.

40. Okwori A, Olabode AO, Emumwen E, Echeonwu G, Lugos M, Okpe E, et al. Sero-epidemiological survey of human cytomegalovirus infection among expectant mothers in Bida, Nigeria. Internet J Infect Dis. 2009;7(1):1-5

41. Lazzarotto T, Spezzacatena P, Pradelli P, Abate DA, Varani S, Landini MP. Avidity of immunoglobulin G directed against human cytomegalovirus during primary and secondary infections in immunocompetent and immunocompromised subjects. Clin Diagn Lab Immunol. 1997 Jul;4(4):469-73.

42. Bodéus M, Feyder S, Goubau P. Avidity of IgG antibodies distinguishes primary from non-primary cytomegalovirus infection in pregnant women. Clin Diagn Virol. 1998 Jan;9(1):9-16.

43. Lazzarotto T, Varani S, Spezzacatena P, Gabrielli L, Pradelli P, Guerra B, et al. Maternal IgG avidity and IgM detected by blot as diagnostic tools to identify pregnant women at risk of transmitting cytomegalovirus. Viral Immunol. 2000;13(1):137-41.

44. Bodéus M, Goubau P. Predictive value of maternal-IgG avidity for congenital human cytomegalovirus infection. J Clin Virol. 1999 Jan;12(1):3-

45. Locatelli F, Percivalle E, Comoli P, Maccario R, Zecca M, Giorgiani G, et al. Human cytomegalovirus (HCMV) infection in paediatric patients given allogeneic bone marrow transplantation: role of early antiviral treatment for HCMV antigenaemia on patients' outcome. Br J Haematol. 1994 Sep;88(1):64-71.

46. Lutz E, Ward KN, Gray JJ. Maturation of antibody avidity after primary human cytomegalovirus infection is delayed in immunosuppressed solid organ transplant patients. J Med Virol. 1994 Dec;44(4):317-22.

47. Lutz E, Ward KN, Szydlo R, Goldman JM. Cytomegalovirus antibody avidity in allogeneic bone marrow recipients: evidence for primary or secondary humoral responses depending on donor immune status. J Med Virol. 1996 May;49(1):61-5.

48. Satilmiş A, Güra A, Ongun H, Mendilcioğlu I, Colak D, Oygür N. CMV seroconversion in pregnants and the incidence of congenital CMV infection. Turk J Pediatr. 2007 Jan-Mar;49(1):30-6.

49. Ruellan-Eugene G, Barjot P, Campet M, Vabret A, Herlicoviez M, Muller $\mathrm{G}$, et al. Evaluation of virological procedures to detect fetal human cytomegalovirus infection: avidity of IgG antibodies, virus detection in amniotic fluid and maternal serum. J Med Virol. 1996 Sep;50(1):9-15.

50. Revello MG, Zavattoni M, Sarasini A, Percivalle E, Simoncini L, Gerna G. Human cytomegalovirus in blood of immunocompetent persons during primary infection: prognostic implications for pregnancy. J Infect Dis. 1998 May;177(5):1170-5.

51. Dangel V, Bäder U, Enders G. Improvement of cytomegalovirus avidity testing by adjusting the concentration of CMV-specific IgG in test samples. J Clin Virol. 2006 Mar;35(3):303-9.

52. Kanengisser-Pines B, Hazan Y, Pines G, Appelman Z. High cytomegalovirus IgG avidity is a reliable indicator of past infection in patients with positive IgM detected during the first trimester of pregnancy. J Perinat Med. 2009;37(1):15-8

53. Boppana SB, Britt WJ. Antiviral antibody responses and intrauterine transmission after primary maternal cytomegalovirus infection. J Infect Dis. 1995 May;171(5):1115-21.

54. Kumar H, Gupta PK, Kumar S, Sarkar RS. Is seroprevalence of anti-IGM CMV among blood donors relevant in India? Indian J Pathol Microbiol. 2008 Jul-Sep;51(3):351-2

55. Adler SP. Immunoprophylaxis against cytomegalovirus disease. Scand J Infect Dis Suppl. 1995;99:105-9. 